Note: This is a preprint of a paper being submitted for publication. Contents of this paper shouid not be quoted nor referred to without permission of the author(s).

CONF-890579--1

DE89 016857

[Presented at the European Materials Research Society Meeting, Strasbourg, France, May 30-June 2, 1989]]

\title{
ION BEAM ANNEALING OF Ga-IMPLANTED Si
}

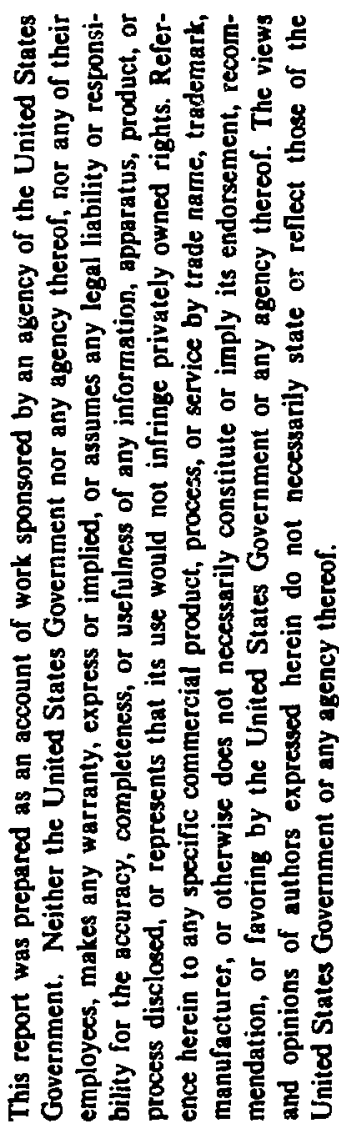

S. P. Withrow, O. W. Holland, and S. J. Pennycook

\author{
The submitted manuscript has been \\ authored by a contractor of the U.S. \\ Govemment under contract No. DE- \\ ACO5-84OR21400 Acoordingly, the U.S. \\ Government retalns a nonexclusive, \\ royalty-free license to publish or \\ reproduce the published form of this \\ contribution, or allow others to do so, \\ for U.S. Covemment purposen" \\ Prepared by the \\ Solid State Division \\ Oak Ridge National Laboratory \\ Oak Ridge, Tennessee 37831 \\ operated by \\ MARTIN MARIETTA ENERGY SYSTEMS, INC. \\ for the \\ U.S. DEPARTMENT OF ENERGY \\ under contract DE-AC05-84OR21400
}




\title{
ION BEAM ANNEALING OF Ga-IMPLANTED Si
}

\author{
S. P. Withrow, O. W. Holland, and S. J. Pennycook \\ Oak Ridge National Laboratory, Oak Ridge, Tennessee 37831 USA
}

\begin{abstract}
Rutherford backscattering/ion channeling and transmission electron microscopy have been used to investigate regrowth effects which occur during highenergy ion bombardment of amorphous silicon layers implanted with $1 \times 10^{16}$ $\mathrm{Ga} / \mathrm{cm}^{2}$. At both 300 and $400^{\circ} \mathrm{C}$ the $\mathrm{Si}$ lattice initially regrows epitaxially. However, at this high dopant level, $\mathrm{Ga}$ is segregated at the crystallineamorphous interface and eventually disrupts epitaxy. Transmission electron microscopy has been used to characterize the lattice morphology and monitor movement of the $\mathrm{Ga}$. The results are compared with thermal annealing effects in Ga-implanted Si samples.
\end{abstract}

\section{Introduction}

Ion-induced damage in $\mathrm{Si}$ at high fluences normally results in the formation of a continuous amorphous layer at the surface which extends through the implanted ion distribution. Recrystallization of this amorphous layer can occur by solid-phase epitaxial growth (SPEG) onto the single-crystal substrate. Thermally activated growth is characterized by a single activation energy $(\sim 2.7 \mathrm{eV})$ over an extended temperature range from 450 to $1360^{\circ} \mathrm{C} .1,2$ Because of the smail activation energy, amorphous layers can be recrystallized with reasonable growth velocities at temperatures as low as $550^{\circ} \mathrm{C}$. The SPEG mechanism has been shown to lead to essentially defect-free annealing of the amorphous layer, with good electrical activation of dopant in the recrystallized volume. ${ }^{3}$ Furthermore, solute trapping at the growth interface can produce highly supersaturated, substitutional solid solutions.4,5

A unique phenomena during SPEG has been observed for Si implanted with high concentrations of low melting point impurities (such as In, Ga, and 
Bi).4,6 Significant redistribution of the dopant occurs due to interfacial transport at the growth interface, which can disrupt normal SPEG and ultimately lead to an amorphous-to-polycrystalline (a-p) transformation. This interfacial transport of dopant has been attributed to the motion of liquid impurity precipitates which form in the a-phase and are collected by the growth interface. 4,7 The formation of these precipitates ahead of the advancing interface has been directly observed by electron microscopy. 8 The liquid droplets are envisioned to move as a result of $\mathrm{Si}$ dissolving into the liquid at the amorphous-liquid boundary, and precipitating at the crystalline-liquid boundary. Free-energy constraints on the total surface energy thermodynamically favor the liquid droplets remaining in contact with the growth interface.7,8 It should be noted that this mechanism is substantially different from impurity segregation phenomena which normally occur at a phase boundary.

There is, however, some controversy in regard to the mechanism for polysilicon nucleation and growth. It has been proposed that polysilicon regrowth originates at the amorphous-crystalline (a-c) boundary during SPEG as a result of an interfacial instability 4 since it was observed that the interface becomes progressively less planar as the quantity of transported dopant increases. At a critical impurity concentration, planar a-c interfacial growth cannot be sustained and further crystallizing occurs by polycrystalline growth originating at the interface. Nygren, however, proposed that SPEG and polycrystalline nucleation/growth were competing processes that depend on temperature and impurity concentration. 9 In this model, the initiation of polysilicon growth is envisioned to occur well ahead of the a-c interface either by explosive crystallization or as a result of a-Si dissolving into molten 
impurity precipitates on one side and crystallizing at the other due to a difference in $\mathrm{Si}$ solubility in equilibrium with a- and c-phases. This has been shown to happen under certain conditions. In actuality, the models are not so different if the melt-mediated growth proposed by Nygren is considered to originate from the a-c interface. This is not unreasonable since most of the impurity droplets are located at the interface prior to polysilicon growth, and their presence inhibits normal SPEG growth, allowing sufficient time for polynucleation.

Recently, it has been shown that SPEG kinetics can be enhanced significantly when the growth interface is irradiated with high-energy ions. ${ }^{10-13}$ The apparent activation energy for SPEG in Si via this ion beam annealing (IBA) is reduced to $0.33 \mathrm{eV}, 14$ thus allowing SPEG of amorphous layers to occur at much lower temperatures. This allows phenomena such as dopant redistribution, solute trapping, and supersaturated alloying, etc., associated with SPEG, to be studied at lower temperatures. In particular, it is of interest to extend the study of SPEG in Si implanted with low melting point impurities to determine the behavior at lower growth temperatures. Lowtemperature growth offers the possibility of affecting solute trapping at the interface, leading to higher impurity saturation in the regrown Si. Furthermore, it provides additional flexibility in studying the novel crystallization mechanism during the a-p transition.

\section{Experimental Procedure}

Silicon (100) crystals were implanted at liquid nitrogen temperature with $180-\mathrm{keV}{ }^{6} \mathrm{Ga}$ ions up to a dose of $1 \times 10^{16} / \mathrm{cm}^{2}$. Regrowth of the silicon crystal lattice was induced by irradiation of the implanted sample using $370-\mathrm{keV}$ 
$28 \mathrm{Si}$ ions at a dose rate of $4 \times 10^{12}$ ions $/ \mathrm{cm}^{2} \mathrm{~s}$ while the sample was held at temperatures ranging from 300 to $400^{\circ} \mathrm{C}$. Part of the sample was masked during irradiation so that effects due only to macroscopic sample heating could be experimentally determined.

Damage to the Si lattice and the distribution and substitutionality of the implanted $\mathrm{Ga}$ were measured in the as-implanted and regrown samples using Rutherford backscattering/ion channeling of $2.0-\mathrm{MeV} \mathrm{He}$ ions. Spectra were obtained with the incident beam aligned along the $\langle 110\rangle$ axial direction or by rotating the sample in the beam to approximate scattering from an amorphous matrix. Lattice morphology and Ga precipitation in the sample were studied using cross-section transmission electron microscopy.

\section{Results and Discussion}

Backscattering yield spectra following ion-assisted growth at $300^{\circ} \mathrm{C}$ of a Si sample implanted with $180-\mathrm{keV}, 1 \times 10^{16} \mathrm{Ga} / \mathrm{cm}^{2}$ are shown in Fig. 1 . Following the $\mathrm{Ga}$ implantation, an amorphous layer is present at the surface which extends to a depth of $\sim 0.32 \mu$ (measured at the half height of the lowenergy edge of the amorphous Si layer). The effect of different fluences of $370-\mathrm{keV} \mathrm{Si}$ ions on the layer is clearly seen. Irradiation with $1 \times 10^{16} \mathrm{Si} / \mathrm{cm}^{2}$ stimulates regrowth to within $0.23 \mu$ of the surface. At this depth the a-c interface is just below the Ga implant (see Fig. 2). The slope in the scartering yield in the vicinity of the a-c interface indicates that the transition region between the amorphous and crystalline phases has remained sharp. During $\mathrm{Si}$ ion irradiation the substrate lattice shows damage at the end of range of the high-energy ions. Irradiation with a higher Si fluence causes a greater amount of regrowth of the a-layer. After $3 \times 10^{16} \mathrm{Si} / \mathrm{cm}^{2}$, the layer has 
regrown through much of the as-implanted $\mathrm{Ga}$ distribution, approaching within $0.08 \mu$ of the Si surface. The a-c interface is still seen to be reasonably sharp. It should be noted that the growth rate per unit dose is lower at this higher dose than for the $1 \times 10^{16} / \mathrm{cm}^{2}$ fluence. Presumably this is because the regrowth penetrates the $\mathrm{Ga}$ distribution and is affected by the high impurity concentration. A similar effect has been observed for thermally activated SPEG; 2 this result is, however, in contrast to results obtained for B- and Pdoped $\mathrm{Si}$ which were found to enhance the growth rate.14 After irradiation with $5 \times 10^{16} \mathrm{Si} / \mathrm{cm}^{2}$ it is clear that ion-assisted growth of the amorphous layer has been interrupted. Little or no additional growth appears to have occurred between 3 and $5 \times 10^{16} / \mathrm{cm}^{2}$. However, the change in slope in the scattering yield in the transition region indicates a much broader and poorly defined interfacial region.

It is of interest to correlate the behavior of the Ga impurity with the regrowth behavior of the $S i$ substrate described above. Random and <110>aligned Rutherford backscattering (RBS) spectra from the Ga-region for conditions corresponding to those in Fig. 1 are shown in Figs. 2 and 3. Essentially no redistribution of $\mathrm{Ga}$ occurs until the a-c growth interface penetrates the Ga profile. This can be seen in Fig. 2 by comparing the scattering yield from $\mathrm{Ga}$ in an as-implanted sample with one after IBA with $1 \times 10^{16} \mathrm{Si} / \mathrm{cm}^{2}$. After IBA with $3 \times 10^{16} \mathrm{Si} / \mathrm{cm}^{2}$, however, the random and aligned yields in this figure clearly show significant redistribution of the $\mathrm{Ga}$ toward the surface. A large Ga peak is seen at a depth of $\sim 0.07 \mu$, which is coincident with the a-c interfacial position for this bombardment dose, but no signific nt movement of $\mathrm{Ga}$ to the surface has occurred. This interfacial transport of $\mathrm{Ga}$ is similar to that which occurs during thermally activated growth. 4 The maximum total 
Ga concentration in the regrown layer at a depth of $0.15 \mu$ is $5 \times 10^{20} / \mathrm{cm}^{3}$. The substitutional fraction of $\mathrm{Ga}$ at this depth was calculated 15 from the aligned spectrum to be $\sim 70 \%$. Tsie total $\mathrm{Ga}$ concentration trapped in the regrown $\mathrm{Si}$ is more than twice that reported for thermally activated growth. 4 The substitutional amount is also larger by about $\sim 40 \%$. The scattering yield from $\mathrm{Ga}$ after IBA with $5 \times 10^{16} \mathrm{Si} / \mathrm{cm}^{2}$ is shown in Fig. 3. Ga is seen to have moved to the surface, although there is still a Ga peak at $0.07 \mu$ similar to that seen in Fig. 2 . Comparing the Ga scattering yield in Fig. 2 to that in Fig. 3 shows that the movement of $\mathrm{Ga}$ toward the surface apparently occurs after a breakdown of the epitaxial regrowth of the Si lattice. Amorphous-to-crystalline interfacial growth appears to occur to about $0.07 \mu$ from the surface, where a Ga peak in observed, before stopping. The peak height in Fig. 3 at $0.07 \mu$ is reduced over that in Fig. 2, indicating that Ga originally at the interface is transported to the surface after the interfacial growth was interrupted. A comparison of the total Ga yield in the as-implanted spectrum and in the random spectra following IBA indicates no $\mathrm{Ga}$ has been lost from the sample. In addition, no change in the as-implanted $\mathrm{Ga}$ distribution as a result of heating to $300^{\circ} \mathrm{C}$ was observed in RBS spectra. The sample was held at $300^{\circ} \mathrm{C} \sim 40$ minutes per $1 \times 10^{16} / \mathrm{cm}^{2} \mathrm{Si}$ dose.

Transmission electron microscopy (TEM) of Sì samples ion beam annealed with $5 \times 10^{16} \mathrm{Si} / \mathrm{cm}^{2}$ at $300^{2} \mathrm{C}$ showed that an a-p transition has occurred in the near-surface region down to 0.07, after SPEG was observed to stop. The redistribution of the $\mathrm{Ga}$ to the surface correlates with this polysilicon formation similar to observations for thermally activated SPEG. 4

Figure 4 shows a cross-sectional transmission electron micrograph of the Si crystal after irradiation with $3 \times 10^{16} \mathrm{Si} / \mathrm{cm}^{2}$. Several interesting features 
are immediately obvious. While there is extensive damage in the region near the end of range of the 370-keV Si ions, no defects are seen in the regrown region. Somewhat more surprising, no Ga precipitates are observed in this region. As indicated above, a significant fraction of the $\mathrm{Ga}$ in this region is not in substitutional sites. Either the nonsubstitutional $\mathrm{Ga}$ is located in very small precipitates ( $<10 \AA$ radius), or it is interstitially dissolved. This behavior is quite different from that reported by Narayan et al. ${ }^{4}$ who observed large precipitates in thermally regrown layers which had been similarly implanted. Also, the interfacial structure is of interest. A continuous amorphous layer is seen ahead of the interface. However, nucleation of polycrystalline Si has clearly occurred in the interfacial region where misoriented polysilicon grains are observed. Hence, polysilicon growth originates from the a-c interface and SPEG becomes inhibited. This polysilicon growth results in significant redistribution of the Ga which was originally at the a-c interface.

Ion-assisted growth at $400^{\circ} \mathrm{C}$ in Ga-implanted $\mathrm{Si}$ has also been studied. At this temperature, interfacial SPEG stops at $\sim 0.12 \mu$ from the surface, indicating that the interfacial breakdown is accelerated at higher temperatures. This is in contrast to the behavior with thermally activated SPEG. In the latter case, the activation energy for SPEG $(2.7 \mathrm{eV})$ is greater than that for the a-p transition $(-1.5 \mathrm{eV})$, so higher tem-peratures would favor SPEG.

Significant redistribution of the Ga occurs when the regrowing interface moves through the implanted region during $400^{\circ} \mathrm{C}$ ion beam annealing. The total concentration of $\mathrm{Ga}$ remaining in the regrown $\mathrm{Si}$ is lower at $400^{\circ} \mathrm{C}$ by more than a factor of 2 from that observed at $300^{\circ} \mathrm{C}$. As at the lower temperature, Ga segregates at the interface. It was shown for the 
$300^{\circ} \mathrm{C}$ anneal that the polysilicon growth originates from an instability at the SPEG interface, presumably due to the build up of $\mathrm{Ga}$. The critical concentration of $\mathrm{Ga}$ needed to produce the a-p instability, as measured in Fig. 3 , is $7 \times 10^{20} / \mathrm{cm}^{3}$. This is the same maximum concentration seen in spectra obtained at $400^{\circ} \mathrm{C}$ in which the measurement of $\mathrm{Ga}$ at the surface suggests that the a-p transition has occurred. This critical concentration of $\mathrm{Ga}$ at the interface occurs deeper in the sample for $400^{\circ} \mathrm{C}$ IBA since a higher fraction of the Ga encountered by the SPEG interface is transported at this temperature. The processes favoring interfacial transport versus trapping in the regrown $\mathrm{Si}$ are not understood. Very little Ga goes substitutional in the Si for IBA at $400^{\circ}$, in contrast to the lower temperature results.

\section{Conclusions}

Solid-phase epitaxial growth of an amorphous, highly Ga-doped Si layer occurs during bombardment with high-energy $\mathrm{Si}$ ions. Defect-free growth, without Ga precipitates, precedes until the onset of an amorphous-topolycrystalline transition at the interface. This transition occurs when the concentration of $\mathrm{Ga}$ transported at the interface as the $\mathrm{Si}$ regrows reaches a critical concentration and additional ion bombardment leads to redistribution of $\mathrm{Ga}$ through the polycrystalline region to the sample surface. The amount of $\mathrm{Ga}$ trapped in the regrown layer is somewhat greater than reported for thermal annealing and is dependent on the temperature of the IBA. Mechanisms favoring transport of $\mathrm{Ga}$ or trapping in the regrown $\mathrm{Si}$ are not known. 


\section{Acknowledgment}

Research sponsored by the Division of Materials Sciences, U.S. Department of Energy under contract DE-AC05-84OR2:400 with Martin Marietta Energy Systems, Inc.

\section{References}

1. L. Csepregi, E. F. Kennedy, T. J. Gallagher, J. W. Mayer, and T. W. Sigmon, J. Appl. Fhys. 48, 4234 (1977).

2. G. L. Olson and J. A. Roth, Materials Science Reports 3, 1988.

3. L.-O. Bauer, in Ion Implantation in Semiconductors, ed. by I. Ruge and J. Graul (Springer-Verlag, Berlin, 1971), p. 70; N. G. Blamires, ibid., p. 119.

4. J. Narayan, O. W. Holland, and B. R. Appleton, J. Vac. Sci. Technol. B 1, 871 (1983).

5. J. S. Williams and R. G. Elliman, Nucl. Instrum. Methods 183, 758 (1981).

6. J. S. Williams and R. G. Elliman, Appl. Phys. Lett. 40, 266 (1982).

7. O. W. Holland, J. Narayan, and D. Fathy, Nucl. Instrum. Methods in Phys. Res. Sect. B 7/8, 243 (1985).

8. S. J. Pennycook and R. J. Culbertson, Mat. Res. Soc. Symp. Proc. 100, 411 (1988).

9. E. Nygren, J. S. Williams, A. Pogany, R. G. Elliman, G. L. Olson, and J. C. McCallum, Mat. Res. Soc. Symp. Proc. 74, 307 (1987).

10. J. Nakata and K. Kajiyama, Appl. Phys. Lett. 40, 686 (1982).

11. J. S. Williams, R. G. Elliman, W. L. Brown, and T. E. Seidel, Phys. Rev. Lett. 55, 1482 (1985).

12. R. G. Elliman, J. S. Williams, W. L. Brown, A. Leiberich, D. M. Maher, and R. V. Knoell, Nucl. Instrum. Methods in Phys. Res. Sect. B 19/20, 435 (1987). 
13. J. Linnros, R. G. Elliman, and W. L. Brown, J. Mater. Res. 3, 1208 (1988).

14. F. Priolo, A. LaFerla, and E. Rimini, J. Mater. Res, 3, 1212 (1988).

15. S. T. Picraux, in New Uses of Ion Accelerators, ed. by J. Ziegler (Plenum, New York, 1975) p. 229. 


\section{Figure Captions}

1. RBS spectra following IBA at $300^{\circ} \mathrm{C}$ of a Si substrate implanted with 180 $\mathrm{keV}, 1 \times 10^{16} \mathrm{Ga} / \mathrm{cm}^{2}$. The Si region is shown for $<110>$ channeling spectra from an as-implanted sample and for different high-energy $\mathrm{Si}$ ion fluences.

2. Comparison of RBS $<110>$ channeling spectra from the Ga region of spectra given in Fig. 1 from an as-implanted sample and for samples ion beam annealed with $\mathrm{Si}$ fluences of 1 and $3 \times 10^{16} / \mathrm{cm}^{2}$. A random spectrum following the higher annealing fluence is also shown.

3. Comparison of random and $<110>$-channeling RBS spectra from the Ga region of a sample implanted with $1 \times 10^{16} \mathrm{Ga} / \mathrm{cm}^{2}$ and then ion beam annealed at $300^{\circ} \mathrm{C}$ with $370-\mathrm{keV} \mathrm{Si}$ ion at a fluence of $5 \times 10^{16} / \mathrm{cm}^{2}$.

4. Cross section transmission electron micrograph of a Si sample implanted with $180-\mathrm{keV}, 1 \times 10^{16} \mathrm{Ga} / \mathrm{cm}^{2}$, followed by IBA at $300^{\circ} \mathrm{C}$ with $370-\mathrm{keV} \mathrm{Si}$ ions at a fluence of $3 \times 10^{16} / \mathrm{cm}^{2}$. 


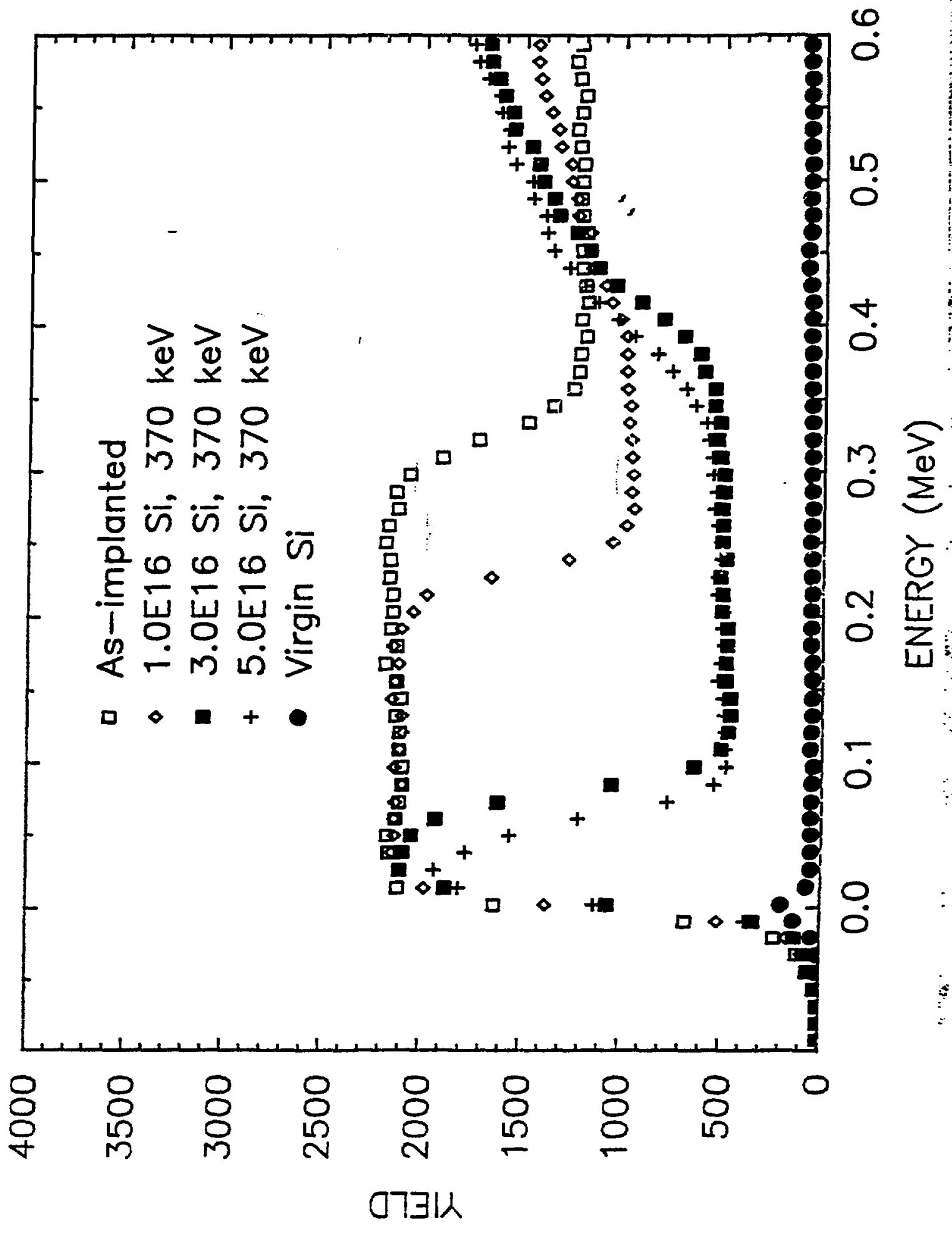




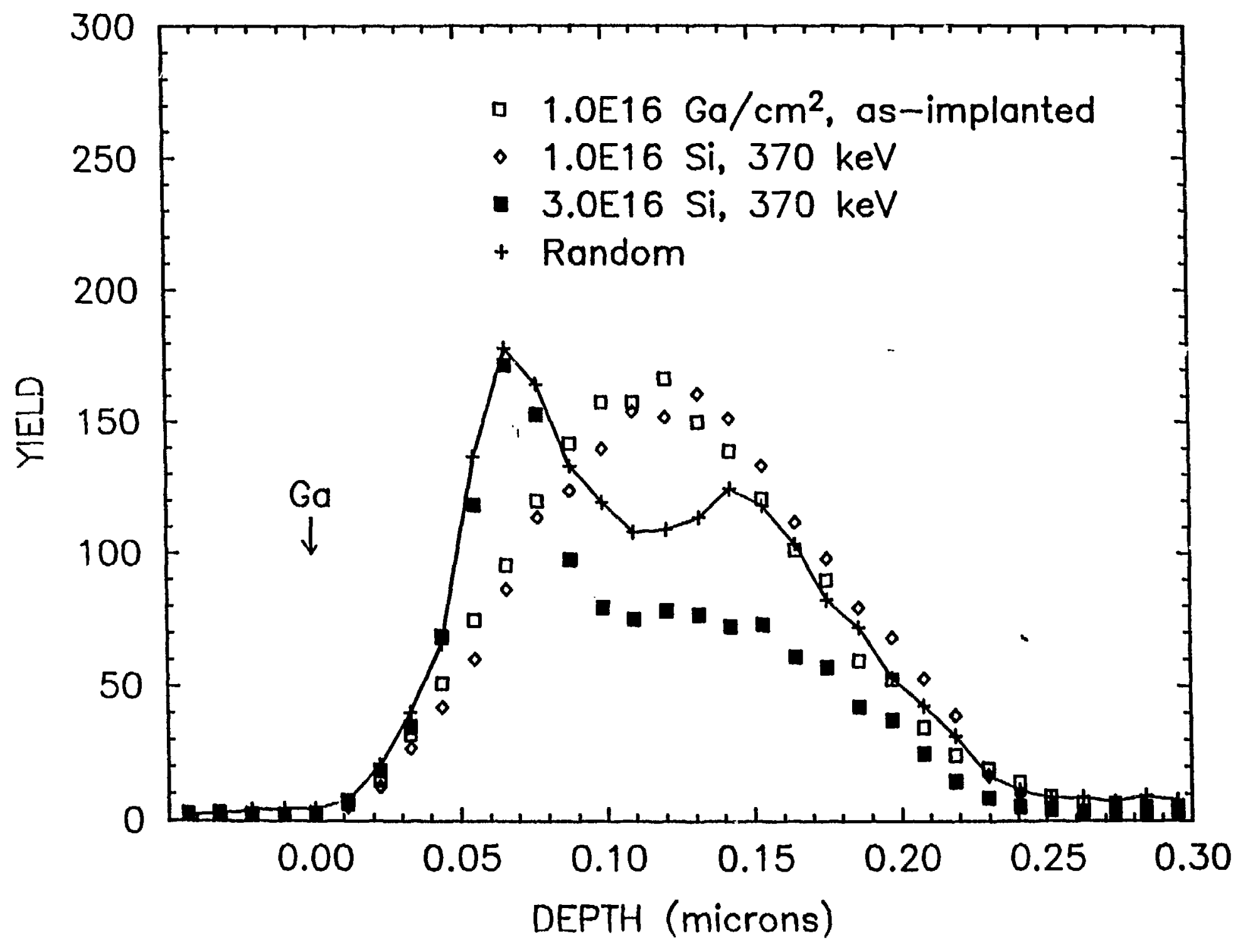




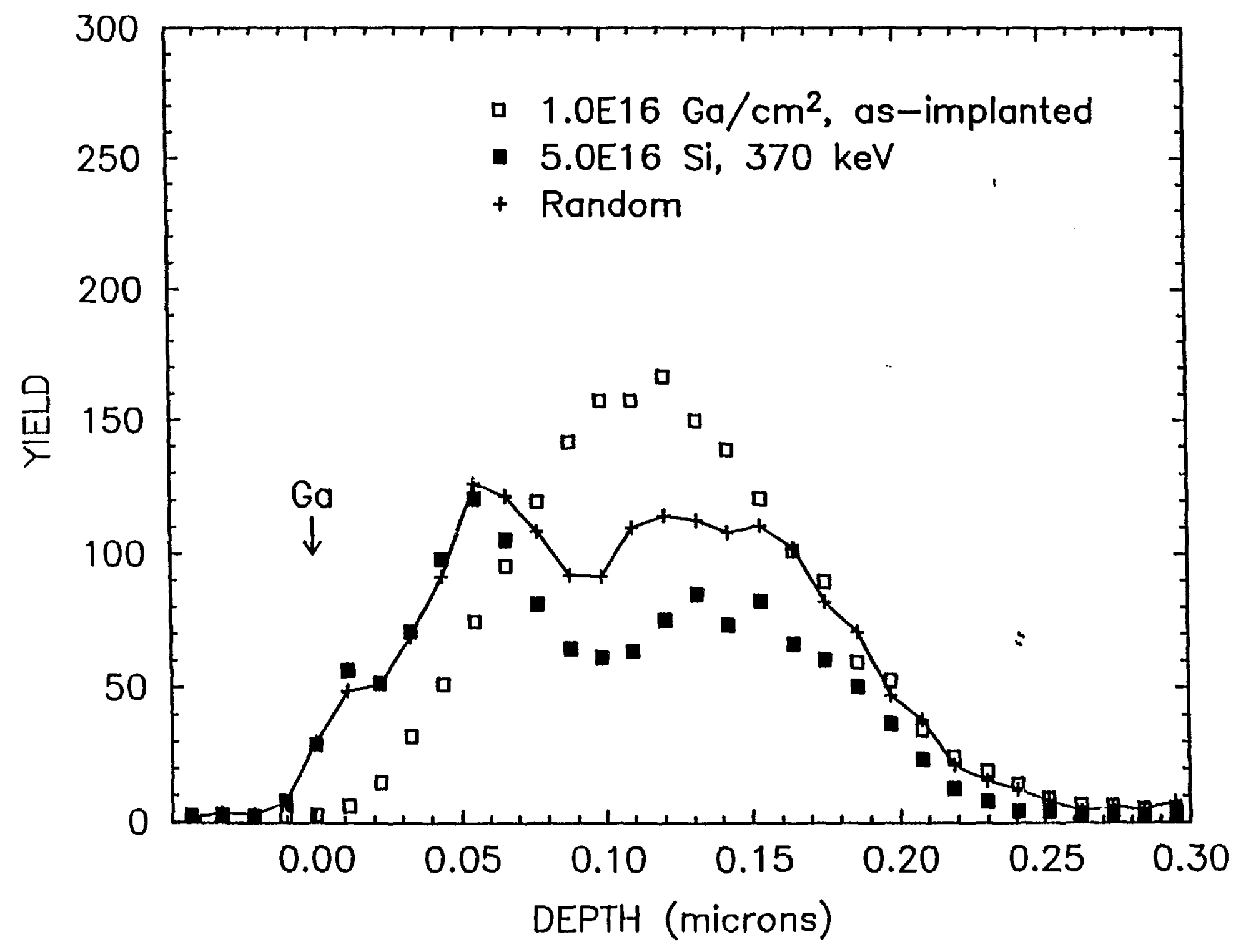




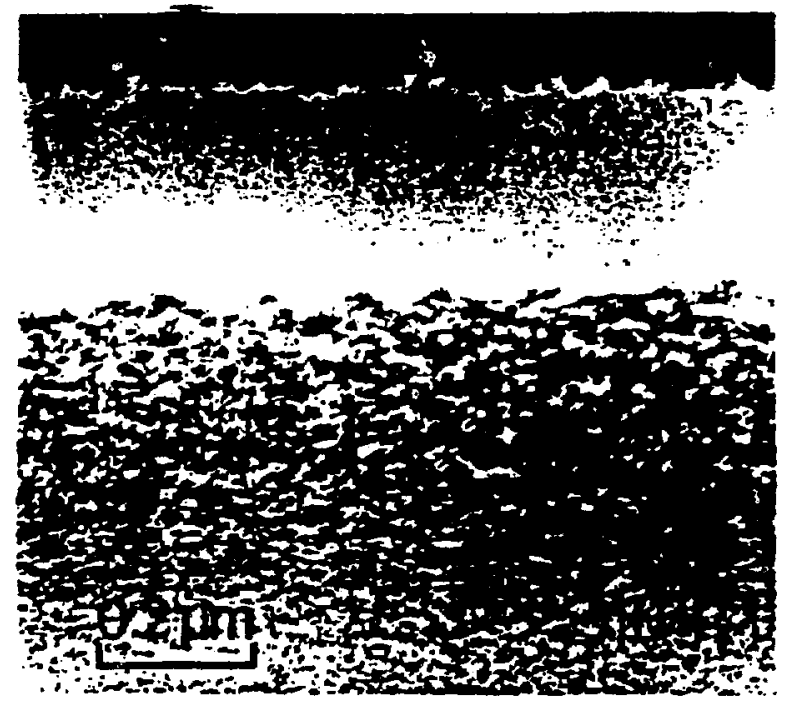

